\title{
Safety and efficacy of tazarotene foam for the treatment of acne vulgaris
}

This article was published in the following Dove Press journal:

Clinical, Cosmetic and Investigational Dermatology

13 May 2013

Number of times this article has been viewed

\section{Erica L Epstein Linda Stein Gold \\ Henry Ford Hospital, Detroit, MI, USA}

Correspondence: Linda Stein Gold Henry Ford Hospital, 6530 Farmington Road, Suite 200, West Bloomfield, MI 48322, USA Email Istein I@hfhs.org
Background: Tazarotene foam is the first topical retinoid foam approved for the treatment of acne vulgaris.

Objective: To review the safety and efficacy studies of tazarotene foam in the treatment of moderate to severe acne.

Methods: Five Phase I safety studies in normal controls are reviewed and two Phase III safety and efficacy studies in patients with moderate to severe acne are reviewed.

Conclusion: Tazarotene foam, $0.1 \%$ was effective in the treatment of moderate to severe acne vulgaris with an acceptable tolerability profile. This treatment provides a cosmetically favorable alternative for topical retinoid therapy.

Keywords: tazarotene, acne, foam, topical retinoid

Tazarotene foam, $0.1 \%$ was US Food and Drug Administration (FDA) approved in 2012 for the treatment of acne vulgaris in patients 12 years old and over. It is the first retinoid in a foam preparation. Tazarotene was first approved in the gel formulation in 1997 and subsequently approved in the cream formulation in 2001. The new foam vehicle is emulsion-based, ethanol-free, and moisturizing. The formulation of the foam vehicle consists of butylated hydroxytoluene, 201 ceteareth-12, citric acid anhydrous, diisopropyl adipate, light mineral oil, potassium citrate 202 monohydrate, potassium sorbate, purified water, and sorbic acid. ${ }^{1}$ It provides a cosmetically elegant delivery system that is easy to apply to large areas. Improved aesthetic properties may lead to enhanced patient compliance.

Topical retinoids are the cornerstone of topical acne therapy. They have several mechanisms of action. They reduce proliferation and cohesion of keratinocytes. They are important in the treatment and prevention of comedonal acne lesions. ${ }^{2-4}$ Retinoids have been shown to modulate specific pathways of inflammation as well. They inhibit the production of inflammatory mediators and chemotactic agents produced by Propionibacterium acnes and immune cells. ${ }^{5,6}$ Retinoids inhibit Toll-like receptor-2, part of the innate immune response that triggers inflammation in acne. This results in a reduction in proinflammatory cytokines. Suppression of activator protein 1 (AP-1) allows for reversal of altered collagen expression and deposition of physiologic collagen and dermal matrix remodeling.

Tazarotene is a prodrug that rapidly hydrolyzes to the active metabolite, tazarotenic acid. Tazarotenic acid is highly bound to proteins. Little tazarotene is detected in the plasma. Tazarotene and tazarotenic acid are eliminated through urinary and fecal pathways. $^{7}$ 
Four Phase I dermal safety studies were performed in healthy volunteers. ${ }^{8,9}$ The potential for cumulative irritation and contact sensitization potential was evaluated in patch test studies conducted over 21 consecutive days. Irritation scores were statistically higher for tazarotene foam $0.1 \%$ as compared with vehicle foam. Some patients underwent rechallenge to evaluate contact sensitization and none displayed conclusive contact sensitization. ${ }^{8}$ Phototoxic and photoallergic potential was also evaluated. Tazarotene foam $0.1 \%$ is not a major photoirritant and has a low potential for phototoxic or photoallergic reactions. ${ }^{9}$

A fifth, and final, Phase I study ${ }^{10}$ was conducted under exaggerated-use conditions in patients with moderate to severe acne to compare the plasma exposure and relative bioavailability of tazarotene foam and tazarotene gel as measured by circulating plasma concentrations of tazarotenic acid. The mean tazarotenic acid area under the curve and maximum concentration values were 1.8 and 2.2-fold higher, respectively, for the gel formulation as compared to the foam formulation. Therefore, tazarotene foam offers less systemic exposure than the gel formulation. ${ }^{10}$

Two Phase III clinical trials were conducted. Patients were between 12 and 45 years of age and had moderate to severe acne. ${ }^{1,11}$ There were two treatment arms with patients randomized 1:1 to active drug versus vehicle treating once daily for 12 weeks. At baseline, $80 \%$ of patients were rated as moderate and $20 \%$ as severe. Subjects had an average of 79.8 total lesions with a mean number of inflammatory lesions of 31.9 and a mean number of noninflammatory lesions of 47.8. The objective of these Phase III trials was to demonstrate superiority over vehicle foam in two out of three lesion counts by week 12 as well as an Investigator's Static Global Assessment (ISGA) of clear or almost clear. Subjects needed to have a two grade improvement in their ISGA. Given that there were no patients with mild acne entered into the study, all patients had at least a two grade improvement to reach a grade of "clear" or "almost clear" on a six point evaluation system of clear, almost clear, mild, moderate, severe, or very severe. ${ }^{1}$ Results from both clinical trials are shown in Table 1. In the clinical trials, all assessments were statistically greater for the tazarotene foam $0.1 \%$ as compared to the vehicle foam. Statistically, more patients on tazarotene foam as compared with vehicle were classified as ISGA of clear or almost clear with at least a two grade improvement by week 4 for one of the Phase III trials ( $8.8 \%$ versus $4.3 \%$ ) and by week 8 for the second trial $(17.3 \%$ versus $11.8 \%) .{ }^{11}$

Safety data is presented in Table 2 . Most adverse reactions were mild to moderate in severity. Severe adverse reactions occurred in $3.0 \%$ of subjects. $2.6 \%$ of patients discontinued the studies due to local skin reactions. ${ }^{1}$

A sub-analysis of the safety and efficacy data in these Phase III trials was also done by race. Overall, $77 \%$ of subjects were white, $15 \%$ were black, and $8 \%$ were other races (eg, Asian or American Indian). There were similar proportions of males (49\%) and females (51\%). Results showed that the tazarotene foam $0.1 \%$ was effective in each racial subgroup. Local irritation peaked at weeks 2 and 4, and then gradually declined. The incidence of tazarotene-related adverse events was similar across races: black (24\%), white (21\%), and other $(23 \%) .^{12}$

Like the other topical tazarotene formulations, tazarotene foam $0.1 \%$ is pregnancy category $\mathrm{X}$. Tazarotene is a teratogenic substance and it is not known what level of exposure is required for teratogenicity in humans. ${ }^{13}$ There were five pregnancies in women who participated in the tazarotene foam studies. Only one subject was exposed

Table I Reductions in lesion counts and improvement in Investigator's Global Assessment at week I2'

\begin{tabular}{|c|c|c|c|c|}
\hline \multirow[t]{2}{*}{ Primary efficacy variables } & \multicolumn{2}{|l|}{ Study I } & \multicolumn{2}{|l|}{ Study 2} \\
\hline & $\begin{array}{l}\text { Tazarotene foam } \\
\mathbf{N}=37 \text { I }\end{array}$ & $\begin{array}{l}\text { Vehicle foam } \\
N=372\end{array}$ & $\begin{array}{l}\text { Tazarotene foam } \\
\mathbf{N}=\mathbf{3 7 3}\end{array}$ & $\begin{array}{l}\text { Vehicle foam } \\
N=369\end{array}$ \\
\hline \multicolumn{5}{|l|}{ Inflammatory lesions } \\
\hline Mean absolute reduction from Baseline & 18.0 & 14.0 & 18.0 & 15.0 \\
\hline Mean percent reduction from Baseline & $58 \%$ & $45 \%$ & $55 \%$ & $45 \%$ \\
\hline \multicolumn{5}{|l|}{ Non-inflammatory lesions } \\
\hline Mean absolute reduction from Baseline & 28.0 & 17.0 & 26.0 & 18.0 \\
\hline Mean percent reduction from Baseline & $55 \%$ & $33 \%$ & $57 \%$ & $41 \%$ \\
\hline \multicolumn{5}{|l|}{ Total lesions } \\
\hline Mean absolute reduction from Baseline & 46.0 & 31.0 & 43.0 & 33.0 \\
\hline Mean percent reduction from Baseline & $56 \%$ & $39 \%$ & $56 \%$ & $43 \%$ \\
\hline \multicolumn{5}{|l|}{ Investigator's Global Assessment, n (\%) } \\
\hline Minimum 2-grade improvement and IGA of 0 or I & 107 (29\%) & $60(16 \%)$ & 103 (28\%) & $49(13 \%)$ \\
\hline
\end{tabular}

Abbreviation: IGA, Investigator's Global Assessment. 
Table 2 Incidence of adverse reactions at the application site in $\geq 1 \%$ of patients treated with tazarotene foam $0.1 \% 1$

\begin{tabular}{lll}
\hline $\begin{array}{l}\text { Adverse reactions at } \\
\text { the application site }\end{array}$ & $\begin{array}{l}\text { Tazarotene foam } \\
\mathbf{N}=\mathbf{7 4 4}\end{array}$ & $\begin{array}{l}\text { Vehicle foam } \\
\mathbf{N}=\mathbf{7 4} \text { I }\end{array}$ \\
\hline $\begin{array}{l}\text { Patients with any adverse } \\
\text { reaction, } \mathrm{n}(\%)\end{array}$ & $163(22)$ & $19(3)$ \\
Irritation & $107(14)$ & $9(\mathrm{I})$ \\
Dryness & $50(7)$ & $8(\mathrm{I})$ \\
Erythema & $48(6)$ & $3(<\mathrm{I})$ \\
Exfoliation & $44(6)$ & $3(<\mathrm{I})$ \\
Pain & $9(\mathrm{I})$ & 0 \\
Photosensitivity & $8(\mathrm{I})$ & $3(<\mathrm{I})$ \\
(including sunburn) & & \\
Pruritus & $7(\mathrm{I})$ & $3(<\mathrm{I})$ \\
Dermatitis & $6(\mathrm{I})$ & $\mathrm{I}(<\mathrm{I})$ \\
\hline
\end{tabular}

to the active drug and her exposure was for 25 days. She delivered a healthy baby. In clinical trials with the other topical tazarotene formulations, nine pregnant women were exposed to the active drug. One woman elected to terminate her pregnancy and the other eight women delivered healthy babies. ${ }^{7,13}$

According to the package insert, topical tazarotene should be avoided in women of child-bearing potential who are contemplating pregnancy or who are unwilling to take adequate precautions to avoid pregnancy. It is recommended that a negative serum or urine pregnancy test be obtained prior to beginning therapy. ${ }^{1}$

Topical tazarotene foam provides an efficacious topical retinoid for the treatment of acne in a unique, cosmetically elegant vehicle. The irritation profile is acceptable and the potential for improved patient compliance exists.

\section{Disclosure}

Dr Stein Gold has been a consultant, investigator and/or speaker for Stiefel, Galderma, Allergan, Valeant Pharmaceuticals, Ferndale, Merz, Taro, Ranbaxy. The other author reports no conflicts of interest in this work.

\section{References}

1. Fabior ${ }^{\circledR}$ (Tazarotene) Foam 0.1\% [package insert]. Research Triangle Park, NC: Stiefel Laboratories, Inc; 2012.

2. Sami N, Harper JC. Topical retinoids. In: Wolverton SE, editor. Comprehensive Dermatologic Drug Therapy, 2nd ed. Philadelphia, PA: WB Saunders; 2007:624-641.

3. Del Rosso JQ. Pharmacotherapy review: topical tazarotene, a composite review of clinical and research experience with focus on optimal use and safety. J Am Osteopath Coll Dermatol. 2004;1(2):55-59.

4. Hui AM, Shalita AR. Topical retinoids. In: Shalita AR, Del Rosso JO, Webster GE, editors. Acne Vulgaris. London: Taylor and Francis Group; 2011:86-94.

5. Millikan LE. The rationale for using a topical retinoid for inflammatory acne. Am J Clin Dermatol. 2003;4(2):75-80.

6. Thiboutot DM, Gollnick HP. Treatment considerations for inflammatory acne: clinical evidence for alapalene $0.1 \%$ in combination therapies J Drugs Dermatol. 2006;5(8):785-794.

7. Tazorac ${ }^{\circledR}$ Gel [package insert]. Irvine, CA: Allergan Inc; 2011.

8. Berg JE, Bowman JP, Saenz AB. Cumulative irritation potential and contact sensitization potential of tazarotene foam $0.1 \%$ in 2 phase 1 patch studies. Cutis. 2012;90(4):206-211.

9. Hogan DJ, Saenz AB. Phototoxic and photoallergic potential of tazarotene foam $0.1 \%$ in 2 phase 1 patch studies. Cutis. 2012;90(5):266-271.

10. Jarratt M, Werner CP, Alió Saenz AB. Tazarotene Foam versus Tazarotene Gel: A Randomized Relative Bioavailability Study in Acne Vulgaris. Clin Drug Investig. 2013;33(4):283-289.

11. Feldman SR, Werner CP, Alió Saenz AB. The Efficacy and Tolerability of Tazarotene Foam, $0.1 \%$ in the Treatment of Acne Vulgaris in 2 multicenter, randomized, vehicle-controlled, double-blind studies. J Drugs Dermatol. 2013;12(4):438-446.

12. Stein Gold L, Jasper S. Tazarotene foam $0.1 \%$ for Acne Vulgaris: analysis of integrated efficacy and safety data by race. Proceedings of the Summer Academy Meeting American Academy of Dermatology, 2012 August 15-19; Boston, USA.

13. Tazorac $^{\circledR}$ cream [package insert]. Irvine, CA: Allergan Inc; 2011.
Clinical, Cosmetic and Investigational Dermatology

\section{Publish your work in this journal}

Clinical, Cosmetic and Investigational Dermatology is an international, peer-reviewed, open access, online journal that focuses on the latest clinical and experimental research in all aspects of skin disease and cosmetic interventions. All areas of dermatology will be covered; contributions will be welcomed from all clinicians and

\section{Dovepress}

basic science researchers globally. This journal is indexed on CAS. The manuscript management system is completely online and includes a very quick and fair peer-review system, which is all easy to use. Visit http://www.dovepress.com/testimonials.php to read real quotes from published authors. 